\title{
Spatio-temporal analysis of the genetic diversity and complexity of Plasmodium falciparum infections in Kedougou, southeastern Senegal
}

Makhtar Niang ${ }^{1 *+}$, Laty G. Thiam ${ }^{1,2+}$, Cheikh Loucoubar ${ }^{3}$, Abdourahmane Sow ${ }^{4}$, Bacary D. Sadio ${ }^{4}$, Mawlouth Diallo ${ }^{5}$, Amadou A. Sall ${ }^{4}$ and Aissatou Toure-Balde ${ }^{1}$

\begin{abstract}
Background: Genetic analyses of the malaria parasite population and its temporal and spatial dynamics could provide an assessment of the effectiveness of disease control strategies. The genetic diversity of Plasmodium falciparum has been poorly documented in Senegal, and limited data are available from the Kedougou Region. This study examines the spatial and temporal variation of the genetic diversity and complexity of $P$. falciparum infections in acute febrile patients in Kedougou, southeastern Senegal. A total of 263 sera from patients presenting with acute febrile illness and attending Kedougou health facilities between July 2009 and July 2013 were obtained from a collection established as part of arbovirus surveillance in Kedougou. Samples identified as $P$. falciparum by nested PCR were characterized for their genetic diversity and complexity using msp-1 and msp-2 polymorphic markers.

Results: Samples containing only P. falciparum accounted for 60.83\% (160/263) of the examined samples. All three msp-1 allelic families (K1, MAD20 and RO33) and two msp-2 allelic families (FC27 and 3D7) were detected in all villages investigated over the 5 -year collection period. The average genotype per allelic family was comparable between villages. Frequencies of $m s p-1$ and $m s p-2$ allelic types showed no correlation with age (Fisher's exact test, $P=0.59$ ) or gender (Fisher's exact test, $P=0.973$ ), and were similarly distributed throughout the 5 -year sampling period (Fisher's exact test, $P=0.412$ ) and across villages (Fisher's exact test, $P=0.866$ ). Mean multiplicity of infection (MOI) for both $m s p-1$ and $m s p-2$ was highest in Kedougou village (2.25 and 2.21, respectively) and among younger patients aged $\leq 15$ years (2.12 and 2.00, respectively). The mean MOI was highest in 2009 and decreased progressively onward.

Conclusion: Characterization of the genetic diversity and complexity of $P$. falciparum infections in Kedougou revealed no spatio-temporal variation in the genetic diversity of $P$. falciparum isolates. However, mean $\mathrm{MOI}$ varied with time of sera collection and decreased over the course of the study (July 2009 to July 2013). This suggests a slow progressive decrease of malaria transmission intensity in Kedougou Region despite the limited impact of preventive and control measures implemented by the National Malaria Control Programme on malaria morbidity and mortality.
\end{abstract}

Keywords: Malaria, Plasmodium falciparum, Transmission, Diversity, Kedougou

\footnotetext{
* Correspondence: mniang@pasteur.sn

${ }^{\dagger}$ Equal contributors

'Institut Pasteur Dakar, Immunology Unit, 36 Avenue Pasteur, BP 220 Dakar,

Senegal

Full list of author information is available at the end of the article
} 


\section{Background}

According to the World Health Organization (WHO), the incidence of malaria and associated mortality respectively decreased by 30 and $47 \%$ globally between 2000 and 2013 [1]. Despite this significant achievement resulting from coordinated malaria preventive and control interventions, an estimated 198 million cases and about 584,000 deaths still occurred worldwide in 2014 [1].

In Senegal, malaria remains a public health concern even though malaria control interventions have successfully reduced the incidence rate nationwide over the last decade [2]. Nonetheless, the situation is particularly worrying in the Southeastern part of the country due to limited impact of applied preventive and control measures [2]. In Kedougou, a region situated in southeastern Senegal, malaria due to Plasmodium falciparum remains highly prevalent $[2,3]$, particularly during the transmission season that coincides with the rainy season from July to November. In 2014, the National Malaria Control Program (NMCP) reported $25.55 \%$ of malaria incidence of which $2.73 \%$ turned into severe disease [2].

Extensive parasite genetic diversity and routine carriage of multiple parasite genotypes by malaria-infected individuals are generally observed in areas of intense malaria transmission $[4,5]$. The genetic diversity of $P$. falciparum parasites is therefore an indicator of malaria transmission intensity, thus serving as a tool to evaluate the effectiveness of malaria control interventions.

The merozoite surface protein-1 (msp-1) and -2 (msp-2) are polymorphic antigenic markers that have been extensively used for genetic characterization of parasite populations in malaria endemic areas but have also served to distinguish new from recrudescent infections during antimalarial drug trials and efficacy studies [6-8].

Despite previous investigations of the genetic diversity of $P$. falciparum in Senegal [9-12], further detailed studies are needed particularly in Kedougou Region where malaria transmission is still active. The present study examined the genetic diversity and complexity or multiplicity of infection (MOI) of P. falciparum infections among febrile patients in Kedougou Region. The spatial and temporal distributions of $m s p-1$ and $m s p-2$ allelic families of $P$. falciparum isolates were also analyzed.

\section{Methods}

\section{Population and study design}

The samples used in this study originated from Kedougou Region (Fig. 1), southeastern Senegal. A detailed description of the study area (climate, rainfall, landscape, fauna, population) has been provided elsewhere [3, 13, 14]. The Kedougou Region borders Guinea, Mali and Gambia between isohyets 1200 and $1300 \mathrm{~mm}$. A total of 263 sera from patients with acute febrile illness (AFI) visiting healthcare facilities (Bandafassi, Kedougou, Ninefesha, Saraya, Khossanto) in Kedougou Region between July 2009 and July 2013 were obtained from a collection established during arbovirus surveillance in Kedougou Region [14]. Due to the similar clinical presentation between malaria and arboviral infection, malaria diagnostic screening was systematically conducted to differentiate arboviral to malaria disease.

AFI was defined as "any patient older than 1 year with a fever (temperature $>38{ }^{\circ} \mathrm{C}$ ) lasting for less than 2 weeks, exhibiting two or more of the following symptoms: headache, myalgia, eye pain, arthralgia, cough, nausea/vomiting, diarrhea, jaundice, bleeding and/or neurological signs".

Sera were investigated for presence of only P. falciparum and subsequently analyzed for genetic diversity, temporal and spatial distribution of allelic families and complexity of malaria infection.

\section{Characterization of malaria parasite species}

To ensure that patients were infected with only $P$. falciparum, all 263 sera were subjected to Plasmodium species characterization following genomic DNA (gDNA) isolation using QIamp DNA Mini Kit (Qiagen, Hilden, Germany) as reported by others $[15,16]$. DNA extracted from blood samples of known microscopically confirmed P. falciparum, $P$. malariae, $P$. vivax and $P$. ovale-infected patients were used as positive controls [3] to discriminate P. falciparum-positive samples from other Plasmodiuminfected samples.

Qualitative detection of Plasmodium parasite DNA was based on a nested PCR approach with primers targeting the Plasmodium spp. $18 \mathrm{~S}$ small subunit ribosomal RNA gene (18S ssrDNA) as described previously [17]. The primary and nested PCR reactions were performed using the GoTaq Green Master Mix protocol (Promega, Madison, USA), according to the manufacturer's recommendations, and amplification conditions were as described previously [3]. Nested PCR results were scored as a categorical variable (presence versus absence of amplification).

\section{Genotyping of Plasmodium falciparum isolates}

Genetic characterization of $P$. falciparum isolates was carried out by nested PCR amplification of the two highly polymorphic regions of $m s p-1$ (block 2 ) and $m s p$ 2 (block 3 ) genes as described previously $[18,19]$. Primer sequences used for amplification of the three allelic families of $m s p-1$ (K1, MAD20 and RO33) and two allelic families of $m s p-2$ (FC27 and 3D7) have been reported elsewhere $[11,19,20]$. An initial amplification of the outer regions of the two genes was followed by a nestedPCR with allelic family specific primer pairs. In the primary PCR reaction, $2 \mu \mathrm{l}$ of gDNA served as template while in the nested reaction, $1 \mu \mathrm{l}$ of the outer PCR product was used as template. Amplification products were 


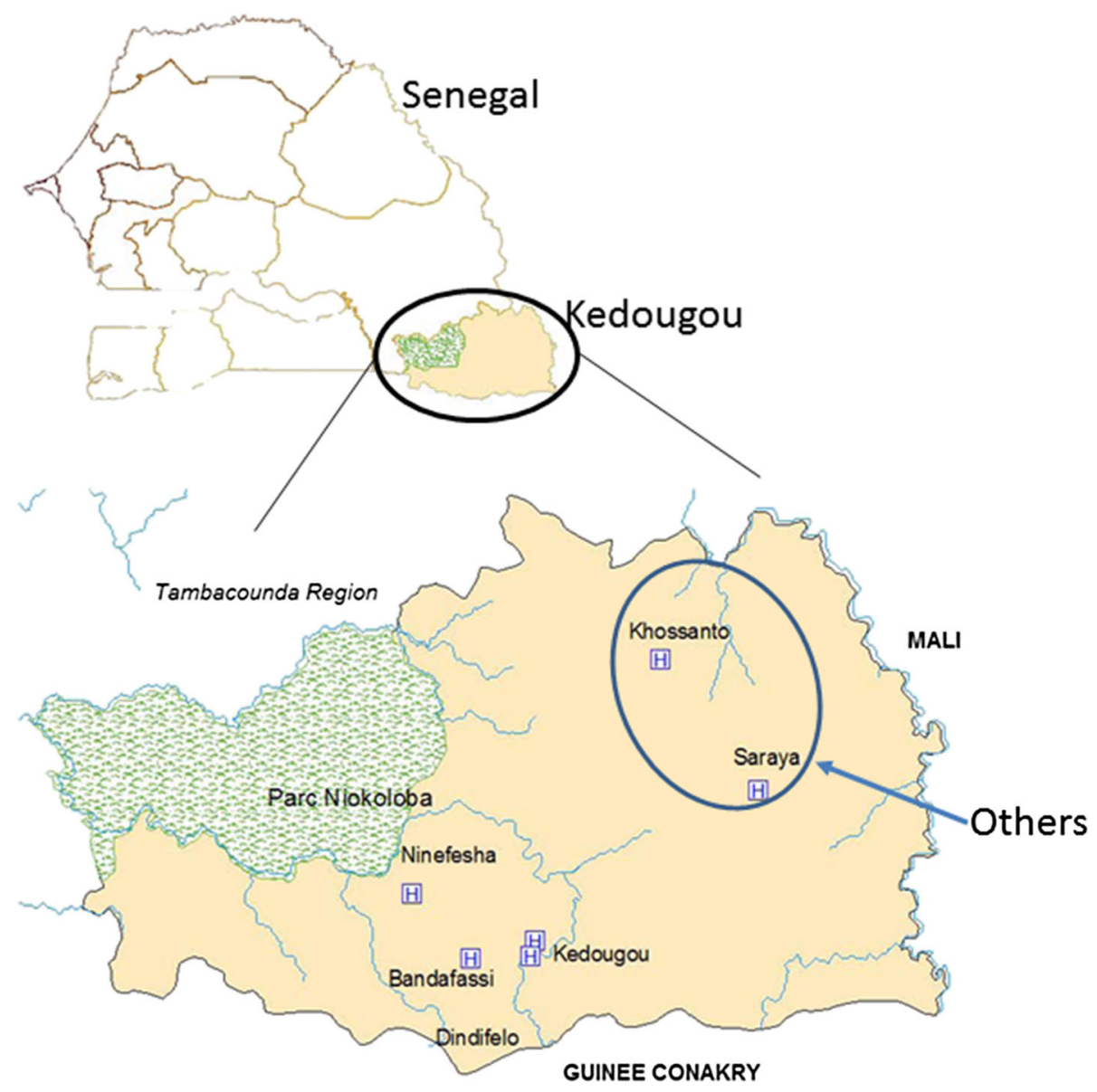

Fig. 1 Map of Kedougou Region showing village of origin of samples. The three major villages (Kedougou, Bandafassi and Ninefesha) where most samples originated are shown, the remaining villages grouped under the term "others" are also shown

separated by electrophoresis on $1.5 \%$ agarose gel, and the fragments were visualized using ethidium bromide under UV light. The sizes of amplified products were determined using a molecular weight marker.

The frequency of each $m s p$ allelic family was calculated as the number of $P$. falciparum isolates containing at least one allele from that family out of the total number of samples. The multiplicity of infection (MOI) or number of genotypes per infection was calculated by dividing the total number of fragments detected in $m s p-1$ or $m s p-2$ by the number of samples positive for the same marker [21, 22].

\section{Statistical analysis}

Data were analyzed using $\mathrm{R}$ statistical software version 3.1.1 (2014-07-10) [23]. Distributions of age and sex between villages were compared using Kruskall-Wallis rank sum test. All comparisons between frequencies were performed using Fisher's exact test. Comparisons were considered statistically significant when $P$-values were less than the Bonferroni-corrected threshold.

\section{Results}

Characteristics of the study population

All 263 serum samples were screened for the presence of Plasmodium parasite DNA and characterization of Plasmodium species [3]. Samples containing only P. falciparum accounted for $60.83 \%$ (160/263) and were further characterized for genetic diversity and MOI using $m s p-1$ and $m s p-2$ polymorphic markers. The demographic characteristics of the $160 \mathrm{P}$. falciparum-positive patients are summarized in Table 1.

Patients ranged in age from one to 65 years old and the majority $(45 \%)$ originated from the village of Bandafassi (Table 1). The mean age of patients was 18 years but varied significantly between villages (Kruskal-Wallis H-test: $\chi^{2}=15.901, d f=3, P=$ 0.0012 ) (Table 1). Most patients (51.25\%) were $\leq$ 15 years despite variations between villages (Fisher's exact test, $P=0.001)$. Among the $160 P$. falciparuminfected patients, $53.75 \%(86 / 160)$ were male and $45.25 \%(74 / 160)$ were female. The sex ratio (M/F) varied between villages and was in favor of males 
Table 1 Baseline characteristics of the study population

\begin{tabular}{|c|c|c|c|c|c|c|}
\hline & $\begin{array}{l}\text { Kedougou } \\
n(\%)\end{array}$ & $\begin{array}{l}\text { Bandafassi } \\
n(\%)\end{array}$ & $\begin{array}{l}\text { Ninefesha } \\
n(\%)\end{array}$ & $\begin{array}{l}\text { Others } \\
n(\%)\end{array}$ & $\begin{array}{l}\text { Total } \\
N(\%)\end{array}$ & $P$-value \\
\hline & $47(29.37)$ & $72(45)$ & $18(11.25)$ & $23(14.37)$ & $160(100)$ & \\
\hline \multicolumn{7}{|l|}{ Age } \\
\hline Mean (yrs) & 22 & 15 & 14 & 23 & 18 & 0.0012 \\
\hline Range (yrs) & $7-60$ & $1-65$ & $2-52$ & $1-59$ & $1-65$ & \\
\hline \multicolumn{7}{|l|}{ Sex } \\
\hline Male & $26(55)$ & $37(51)$ & $8(44)$ & $14(61)$ & 86 (53.75) & \\
\hline Female & $21(45)$ & 35 (49) & $10(56)$ & $9(39)$ & $74(45.25)$ & \\
\hline Ratio (M/F) & 1.23 & 1.05 & 0.8 & 1.55 & 1.16 & 0.743 \\
\hline \multicolumn{7}{|l|}{ Age group } \\
\hline$\leq 15$ years & $14(29.79)$ & 47 (65.28) & $12(66.66)$ & 9 (39.13) & $82(51.25)$ & \\
\hline$>15$ years & $33(70.21)$ & $25(34.72)$ & $6(33.33)$ & $14(60.87)$ & 78 (48.75) & 0.001 \\
\hline
\end{tabular}

except for Ninefesha (Table 1), although this difference was not significant (Kruskall Wallis rank test, $P$ $=0.743)$.

\section{Genetic diversity of Plasmodium falciparum isolates}

All three allelic families of $m s p-1$ (K1, MAD20 and RO33) and two of $m s p-2$ (3D7 and FC27) were detected among the $160 P$. falciparum positive isolates genotyped in this study.

Of the detected $m s p-1$ genotypes, $41.45 \%$ (182/439) belonged to the MAD20 allelic family while $\mathrm{K} 1$ and RO33 allelic families represented $34.16 \%$ (150/439) and $24.37 \%$ (107/439), respectively (Table 2). The 3D7 allelic type was the predominant $m s p-2$ genotype representing $77.89 \%(215 / 276)$ of detected $m s p-2$ genotypes while the FC27 allelic type represented only $22.10 \%(61 / 276)$ of msp-2 genotypes (Table 2).

Although the total number of genotypes was highest in $P$. falciparum isolates obtained from Bandafassi (Table 2), the mean number of genotypes per allelic family was comparable between villages.

\section{Frequency of $m s p-1$ and $m s p-2$ allelic families}

All individual $m s p-1$ and $m s p-2$ allelic families, dimorphic combinations of $m s p-1$ (K1/MAD20, K1/RO33 and MAD20/RO33) and $m s p-2$ (FC27/3D7), and trimorphic combination of $m s p-1$ (K1/MAD20/RO33) were observed at varying proportions in $P$. falciparum isolates from Kedougou Region (Fig. 2).

Concerning the $m s p-1$ locus, the K1 and MAD20 allelic families were the most represented and were identified in $89.37 \%(143 / 160)$ and $87.5 \%(140 / 160)$ of samples, respectively, while the RO33 allelic family was present in $62.5 \%$ (100/160) of samples (Fig. 2a). Dimorphic $m s p-1$ allelic combinations accounted for 30\% (48/160), 10.62\% $(17 / 160)$ and $4.37 \%(7 / 160)$ of $m s p-1$ positive samples for K1/MAD20, K1/RO33 and MAD20/RO33, respectively, while the percentage of samples carrying the three $m s p-1$ allelic families (K1/MAD20/RO33) was 47.5\% (76/160) (Fig. 2b).

With respect to $m s p-2$, the frequency of samples with only the 3D7 allelic family [96.25\% (154/160)] was found to be significantly higher (Fisher's exact test, $P<0.001$ ) than those harboring only the FC27 allelic family [29.37\% (47/160)] (Fig. 2a). Dimorphic FC27/3D7 allelic combination was identified in $28.75 \%$ (46/160) of samples (Fig. 2b).

\section{Frequency of $m s p-1$ and $m s p-2$ allelic types with respect to age and gender}

The frequencies of $m s p-1$ and $m s p-2$ allelic types were categorized within two arbitrarily defined age groups: s 15 years and $>15$ years (Table 1 ). Frequencies of the three $m s p-1$ allelic types (K1, MAD20 and RO33) and two $m s p$ -

Table 2 Total and mean number of genotypes per allelic family

\begin{tabular}{|c|c|c|c|c|c|c|c|}
\hline \multirow[t]{2}{*}{ Village } & \multicolumn{3}{|l|}{$m s p-1$} & \multirow[t]{2}{*}{ Total } & \multicolumn{2}{|l|}{$m s p-2$} & \multirow[t]{2}{*}{ Total } \\
\hline & $\mathrm{K} 1$ & MAD20 & $\mathrm{RO} 33$ & & FC27 & 3D7 & \\
\hline Kedougou & $47(1.00)$ & $51(1.08)$ & $37(0.78)$ & 135 & $16(0.34)$ & $46(0.97)$ & 62 \\
\hline Bandafassi & $65(0.90)$ & 85 (1.18) & $42(0.58)$ & 192 & $34(0.47)$ & $113(1.56)$ & 147 \\
\hline Ninefesha & $17(0.94)$ & $18(1.00)$ & $8(0.44)$ & 43 & $6(0.33)$ & $32(1.77)$ & 38 \\
\hline Others & $21(0.91)$ & $28(1.21)$ & $20(0.86)$ & 69 & $5(0.21)$ & $21(1.04)$ & 29 \\
\hline Total & 150 & 182 & 107 & 439 & 61 & 215 & 276 \\
\hline
\end{tabular}




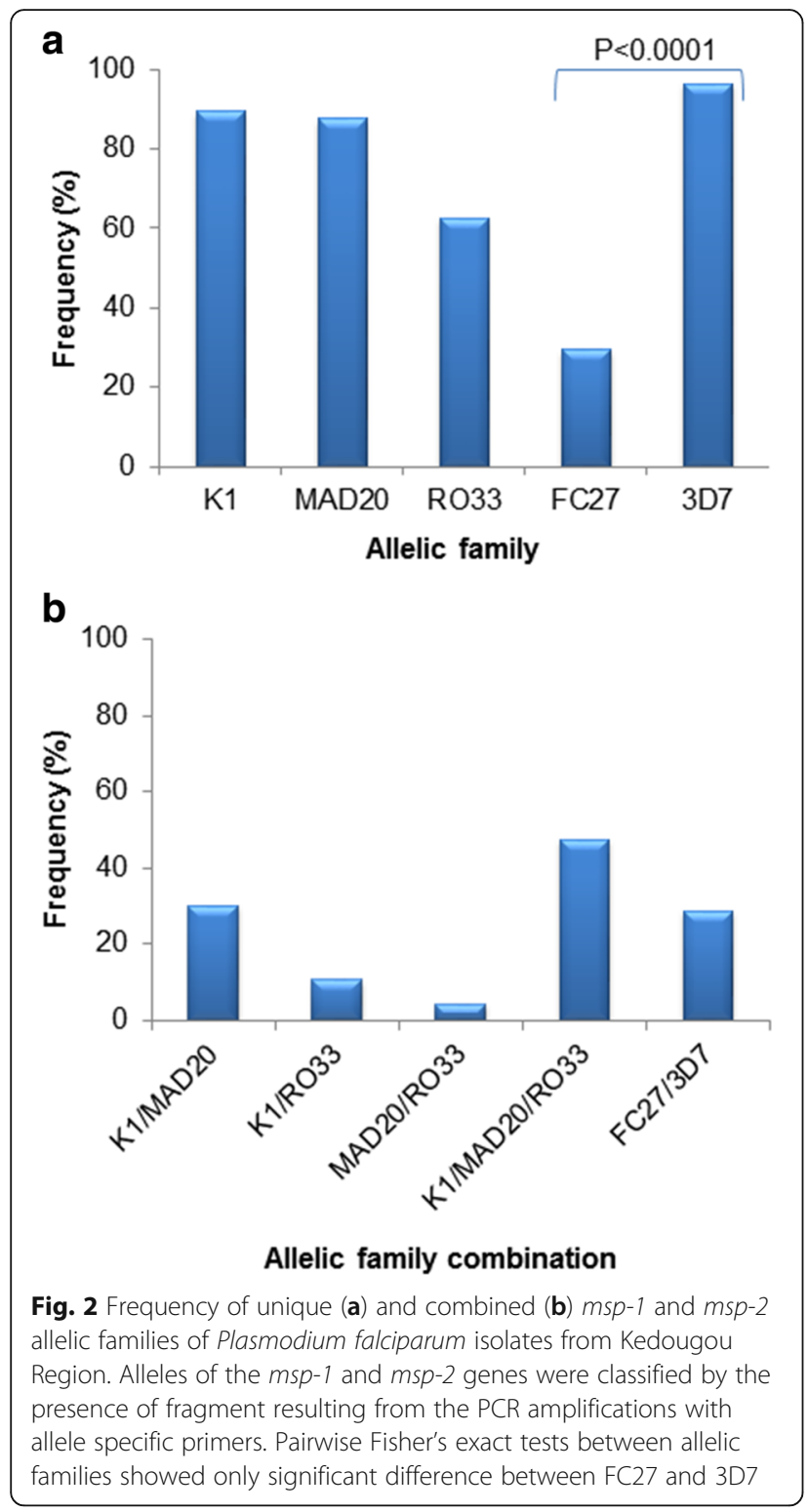

2 allelic types (FC27 and 3D7) were similarly distributed with no significant differences between age groups (Fisher's exact test, $P=0.59$ ) (Fig. 3a). Within a given age group, frequencies of the three $m s p-1$ allelic types and the two $m s p-2$ allelic types were also comparable.

With respect to gender, frequencies of $m s p-1$ and $m s p$ 2 allelic families showed similar distribution between males and females with no significant difference observed (Fisher's exact test, $P=0.973$ ). The frequencies of all $m s p-1$ and $m s p-2$ allelic families were also comparable within a given gender (Fig. 3b).

\section{Temporal and spatial distribution of $m s p-1$ and $m s p-2$ allelic families in Kedougou Region}

Analysis of the spatio-temporal distribution of all $m s p-1$ and $m s p-2$ allelic families of $P$. falciparum isolates from

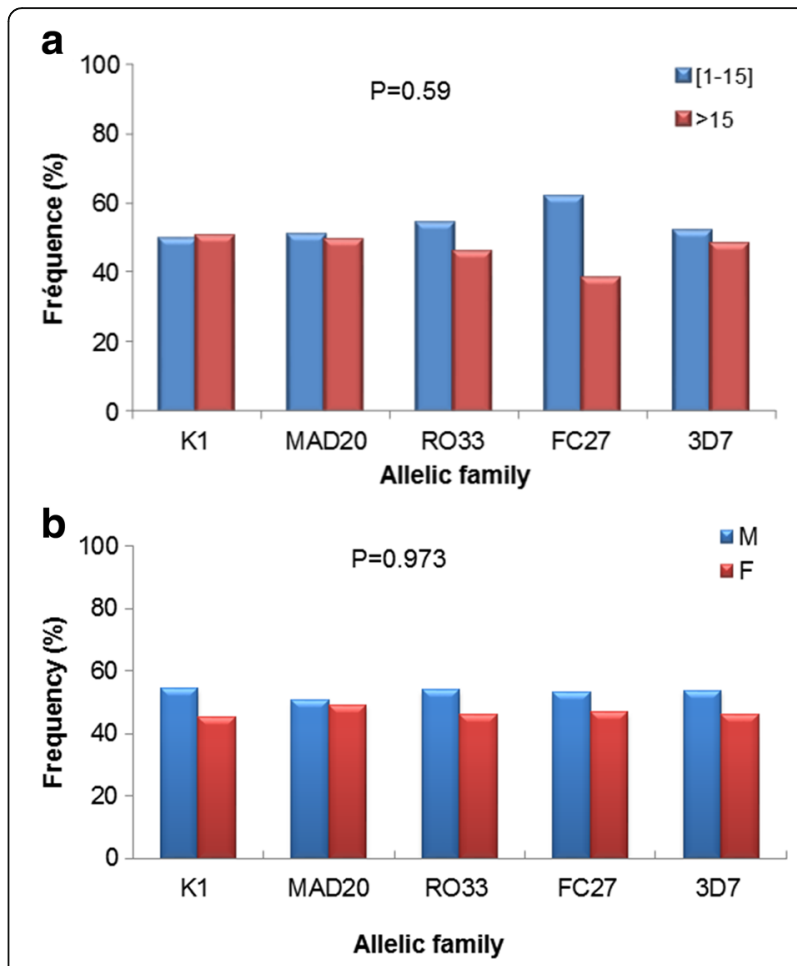

Fig. 3 Distribution of frequencies of $m s p-1$ and $m s p-2$ allelic families according to age group (a) and gender (b). Frequencies were determined as the percentage of individuals within a given age group or gender among the positive samples. Statistical differences were determined using Fisher's exact test

2009 to 2013 showed no significant difference (Fisher's exact test, $P=0.412$ ) throughout the 5-year sampling period (Fig. 4a). Allelic frequencies were highest in 2009 and decreased progressively up to 2013 except for RO33 in 2011 (Fig. 4a). The distribution of allelic frequencies was also similar (Fisher's exact test, $P=0.866$ ) between villages with a consistent low frequency of all allelic types in Ninefesha (Fig. 4b), probably related to the lower number of samples from this village.

\section{Mean multiplicity of infection in relation to village, age and sampling period}

Mean MOI was compared between villages (Kedougou, Bandafassi, Ninefesha and others), age groups ( $\leq 15$ years and $>15$ years), and sampling periods (2009 to 2013). The mean MOI for both $m s p-1$ and $m s p-2$ was found to be higher in $P$. falciparum isolates from patients from Kedougou village $(\mathrm{MOI}=2.25$ and 2.21$)$, in patients aged $\leq 15$ years $(\mathrm{MOI}=2.12$ and 2.00$)$, and those diagnosed in 2009 (MOI = 2.21 and 2.50) than P. falciparum isolates originating from others villages, patients aged older than 15 years, and those diagnosed from 2010 onward, respectively (Table 3). Overall, the mean MOI varied between villages for both loci and decreased progressively 

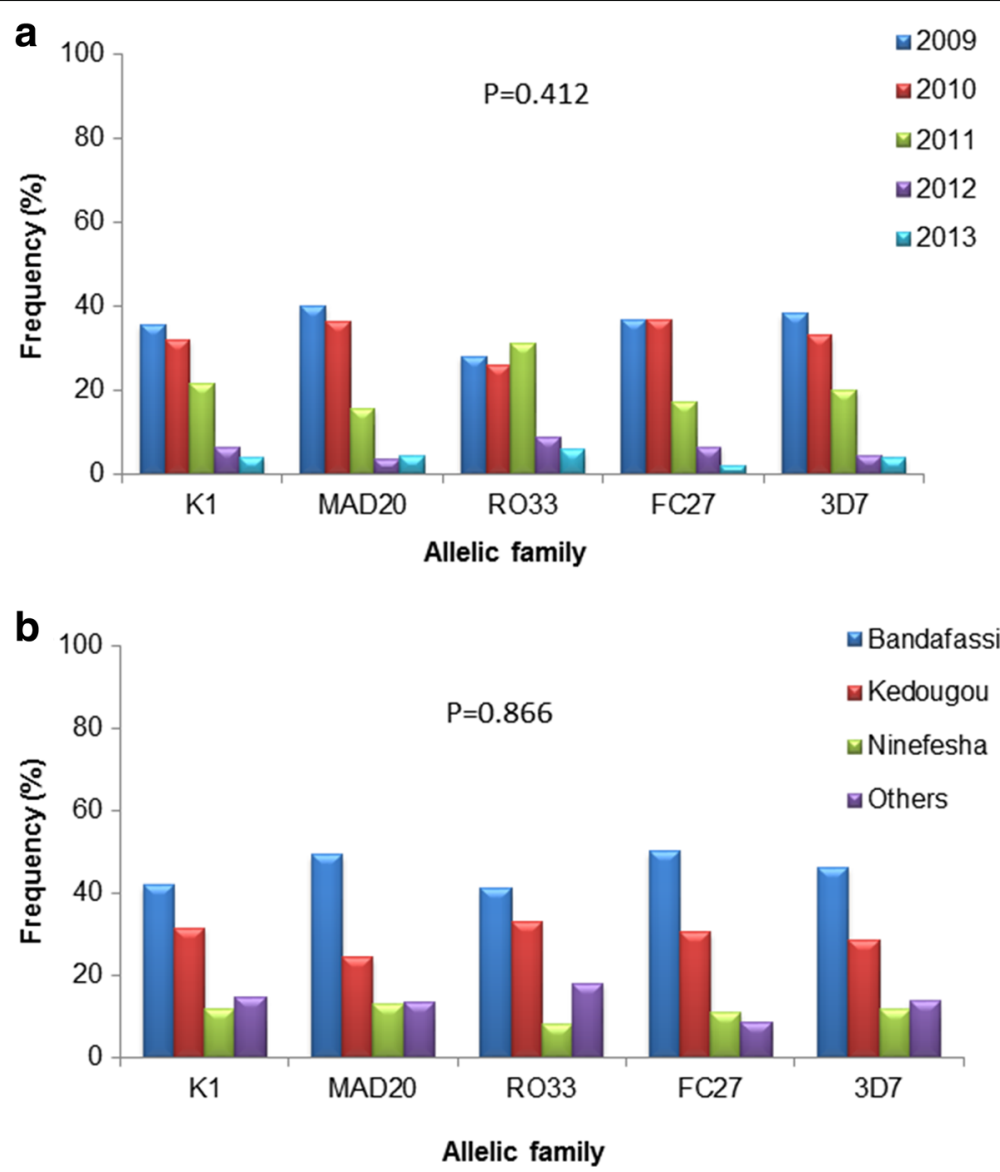

Fig. 4 Temporal (a) and spatial (b) distribution of $m s p-1$ and $m s p-2$ allelic families in Kedougou Region. Frequencies of allelic families according to period (temporal distribution) or village (spatial distribution) were calculated as the percentage of samples positive for a given allelic family for a period or village out of the total positive samples. Statistical differences were determined using Fisher's exact test

with increasing age and year of sample collection for both $m s p-1$ and $m s p-2$ loci (Table 2).

\section{Discussion}

The present study provides information about the spatial and temporal dynamics of the $P$. falciparum parasite population among febrile patients in Kedougou Region. This bridges an important gap in the understanding of the molecular characteristics of the parasite population in this region where Plasmodium transmission is still active and could inform efforts to monitor and control Plasmodium transmission in this region.

All $m s p-1$ and $m s p-2$ allelic families were represented in all villages in Kedougou Region where samples were collected and elevated frequencies of $m s p-1$ and $m s p-2$ genotypes were reported with MAD20 and 3D7 being the most prevalent, particularly in Bandafassi and Kedougou villages. However, the comparable average number of genotypes for each locus between villages suggested that the large number of genotypes in Bandafassi potentially reflects an elevated number of samples rather than higher genetic diversity of $P$. falciparum isolates in this village.

FC27 allelic type has been shown to be more prevalent in asymptomatic rather than symptomatic Plasmodiuminfected individuals [24], suggesting a lower risk of developing symptomatic malaria with increasing carriage of isolates belonging to the FC27 allelic family. Such observations are supported by previous studies in Senegal $[5,13]$ and Nigeria [25] but contrast with data from Benin and Gabon [26, 27], emphasizing the need for multicentric studies using P. falciparum isolates from both asymptomatic and symptomatic individuals to comprehensively establish the potential relationship between specific allele carriage and disease outcome. High to moderate mean MOI was observed among $P$. falciparum isolates across all the studied villages with the highest mean MOI being observed in Kedougou village. A high MOI is a common feature in most malaria hyperendemic areas [28-30] and has been directly linked with malaria transmission intensity $[22,28,30]$. Thus, the slow decrease of the mean MOI for both msp-1 and 
Table 3 Mean multiplicity of infection (MOI) among the study participants with respect to sample origin, age and period of collection

\begin{tabular}{llll}
\hline & No. of samples & \multicolumn{2}{l}{ Mean MOI } \\
\cline { 3 - 4 } & & msp-1 & $m s p-2$ \\
\hline Village & & 2.25 & 2.21 \\
Kedougou & 47 & 1.73 & 2.06 \\
Bandafassi & 72 & 1.79 & 1.82 \\
Ninefesha & 18 & 1.76 & 1.62 \\
Others & 23 & & \\
Age group & & 2.12 & 2.00 \\
$\leq 15$ years & 82 & 1.64 & 1.84 \\
$>15$ years & 78 & & \\
Year & & 2.21 & 2.50 \\
2009 & 61 & 2.05 & 2.25 \\
2010 & 51 & 1.90 & 1.95 \\
2011 & 32 & 1.65 & 1.70 \\
2012 & 9 & 1.60 & 1.20 \\
2013 & 7 & &
\end{tabular}

msp-2 loci from 2009 to 2013 in Kedougou Region could suggest a progressive decrease of Plasmodium transmission although a lack of data prior major interventions by the NMCP in Kedougou Region does not allow for a thorough comparison.

To date, only a few studies have applied genetic surveillance tools to evaluate Plasmodium population structure in relation to changing malaria transmission in Senegal, thus precluding a meaningful comparison with the situation observed in Kedougou Region. The application of molecular barcoding genomic surveillance on $P$. falciparum parasites collected from Thies region (West Senegal) between 2006 and 2013 revealed reduced genetic diversity of $P$. falciparum population along with a decline of Plasmodium transmission from 2006 to 2010, a period transcending the introduction of insecticide-treated bednets in 2008 [31]. The mass distribution of insecticide-treated bednets in malaria-endemic countries was demonstrated to be a key player in the dramatic decline of Plasmodium transmission documented in Senegal [32, 33] and elsewhere [34].

The finding that MOI decreased with age supports studies conducted in other countries $[35,36]$ that have shown lower MOI in those aged 15 and above. The existence of a positive association between high childhood MOI and low adulthood MOI is in keeping with the concept that exposure to multiple strains of the parasite in early life is necessary to produce immunity in adults. Conflicting findings indicating a greater $\mathrm{MOI}$ in older individuals have also been reported [29,37]. The limited studies on $P$. falciparum genetic diversity conducted in Senegal failed to establish a link between MOI and age groups [10-12], thus depicting the complex nature of such an association. The lack of an association between MOI and age groups as reported in above-mentioned studies suggests that the MOI is not directly related to the period of acquisition of immunity, but rather reflects the exposure of subjects to malaria in an endemic area. The decrease of MOI over time despite the limited impact of control measures suggested a selection of clonal parasites populations, thus increasing the chance of an individual being re-infected with the same allele.

\section{Conclusions}

This study reports the spatial and temporal variation of the genetic diversity and complexity of $P$. falciparum infections in acute febrile patients in Kedougou, a Senegalese region with active malaria transmission. The findings revealed that $P$. falciparum isolates of Kedougou Region are highly diverse with limited spatio-temporal variation in the region. However, MOI decreased over time, which may be an indication of a progressive reduction in Plasmodium transmission in the region despite the limited impact of control measures on malaria morbidity and mortality in the area.

Additional studies that examine the dynamics of the genetic diversity of $P$. falciparum parasite populations, considering factors such as the malaria transmission intensity based on entomological inoculation rates and the immune status of $P$. falciparum-infected individuals would tremendously improve our understanding of $P$. falciparum parasite diversity in Kedougou Region and contribute to guide malaria interventions.

\section{Abbreviations}

AFI: Acute febrile illness; MOl: Multiplicity of infection; NMCP: National Malaria Control Programme; WHO: World Health Organization

\section{Acknowledgements}

The authors express their gratitude to the population, healthcare workers and medical authorities in Kedougou Region for their support and cooperation in conducting this study.

\section{Funding}

This research was supported by the United States National Institutes of Health (NIH) Grant Number Al1069145 and Institute Pasteur de Dakar.

\section{Availability of data and material}

The datasets supporting the conclusions of this article are included within the article.

\section{Authors' contributions}

$M N, C L, A S, A A S$ and ATB conceived and designed the study. MN and LGT performed the experiments. MN, LGT, CL, AAS and ATB analyzed and interpreted the data. MD, AS, BDS and AAS organized the recruitment of patients and sample collection. MN and CL performed the statistical analyses. $M N, L G T, C L, A S, A A S$ and AT wrote the manuscript. All authors read and approved the final manuscript.

Competing interests

The authors declare that they have no competing interests. 


\section{Consent for publication}

Not applicable.

\section{Ethics statement and consent to participate}

The study objectives, benefits and risks were explained in French language or local dialects to all participants before inclusion. Written informed consent was obtained from adult participants and from the parents or legal guardians of children. The study was examined and approved by the Senegalese National Health Research Ethical Committee.

\section{Author details}

${ }^{1}$ Institut Pasteur Dakar, Immunology Unit, 36 Avenue Pasteur, BP 220 Dakar, Senegal. ${ }^{2}$ Department of Animal Biology, Cheikh Anta Diop University of Dakar, Dakar, Senegal. ${ }^{3}$ Institut Pasteur Dakar, Biostatistics, Bioinformatics and Modeling Group, 36 Avenue Pasteur, BP 220 Dakar, Senegal. ${ }^{4}$ Institut Pasteur Dakar, Arbovirus and Viral Hemorrhagic Fevers Unit, 36 Avenue Pasteur, BP 220 Dakar, Senegal. ${ }^{5}$ Institut Pasteur Dakar, Medical Entomology Unit, 36 Avenue Pasteur, BP 220 Dakar, Senegal.

Received: 15 June 2016 Accepted: 10 January 2017

Published online: 19 January 2017

\section{References}

1. World Health Organization. World Malaria Report 2014. Geneva: WHO; 2015.

2. Programme National de Lutte contre le Paludisme. Bulletin Epidemiologique Annuel du Paludisme au Senegal. Senegal: PNLP. 2015; p 24.

3. Niang M, Thiam LG, Sow A, Loucoubar C, Bob NS, Diop F, et al. A molecular survey of acute febrile illnesses reveals Plasmodium vivax infections in Kedougou, southeastern Senegal. Malar J. 2015;14:281.

4. Contamin H, Fandeur T, Rogier C, Bonnefoy S, Konate L, Trape JF, et al. Different genetic characteristics of Plasmodium falciparum isolates collected during successive clinical malaria episodes in Senegalese children. Am J Trop Med Hyg. 1996;54(6):632-43.

5. Robert F, Ntoumi F, Angel G, Candito D, Rogier C, Fandeur T, et al. Extensive genetic diversity of Plasmodium falciparum isolates collected from patients with severe malaria in Dakar, Senegal. Trans R Soc Trop Med Hyg. 1996; 90(6):704-11.

6. Mugittu K, Priotto G, Guthmann JP, Kiguli J, Adjuik M, Snounou G, et al. Molecular genotyping in a malaria treatment trial in Uganda - unexpected high rate of new infections within 2 weeks after treatment. Trop Med Int Health. 2007;12(2):219-23.

7. Sondo P, Derra K, Diallo-Nakanabo S, Tarnagda Z, Zampa O, Kazienga A, et al. Effectiveness and safety of artemether-lumefantrine versus artesunateamodiaquine for unsupervised treatment of uncomplicated falciparum malaria in patients of all age groups in Nanoro, Burkina Faso: a randomized open label trial. Malar J. 2015:14(1):325.

8. Laochan N, Zaloumis SG, Imwong M, Lek-Uthai U, Brockman A, Sriprawat $K$, et al. Intervals to Plasmodium falciparum recurrence after anti-malarial treatment in pregnancy: a longitudinal prospective cohort. Malar J. 2015:14:221.

9. Henry M, Diallo I, Bordes J, Ka S, Pradines B, Diatta B, et al. Urban malaria in Dakar, Senegal: chemosusceptibility and genetic diversity of Plasmodium falciparum isolates. Am J Trop Med Hyg. 2006;75(1):146-51.

10. Konate L, Zwetyenga J, Rogier C, Bischoff E, Fontenille D, Tall A, et al. Variation of Plasmodium falciparum msp1 block 2 and msp2 allele prevalence and of infection complexity in two neighbouring Senegalese villages with different transmission conditions. Trans R Soc Trop Med Hyg 1999;93 Suppl 1:21-8.

11. Vafa M, Troye-Blomberg M, Anchang J, Garcia A, Migot-Nabias F. Multiplicity of Plasmodium falciparum infection in asymptomatic children in Senegal: relation to transmission, age and erythrocyte variants. Malar J. 2008;7:17.

12. Zwetyenga J, Rogier C, Tall A, Fontenille D, Snounou G, Trape JF, et al. No influence of age on infection complexity and allelic distribution in Plasmodium falciparum infections in Ndiop, a Senegalese village with seasonal, mesoendemic malaria. Am J Trop Med Hyg. 1998;59(5):726-35.

13. Niang M, Loucoubar C, Sow A, Diagne MM, Faye O, Diallo M, et al. Genetic diversity of Plasmodium falciparum isolates from concurrent malaria and arbovirus co-infections in Kedougou, southeastern Senegal. Malar J. 2016; 15(1):155.
14. Sow A, Loucoubar C, Diallo D, Faye O, Ndiaye Y, Senghor CS, et al. Concurrent malaria and arbovirus infections in Kedougou, southeastern Senegal. Malar J. 2016;15(1):47.

15. Bharti AR, Patra KP, Chuquiyauri R, Kosek M, Gilman RH, Llanos-Cuentas A et al. Polymerase chain reaction detection of Plasmodium vivax and Plasmodium falciparum DNA from stored serum samples: implications for retrospective diagnosis of malaria. Am J Trop Med Hyg. 2007;77:444-6.

16. Gal S, Fidler C, Turner S, Lo YM, Roberts DJ, Wainscoat JS. Detection of Plasmodium falciparum DNA in plasma. Ann N Y Acad Sci. 2001;945:234-8.

17. Snounou G, Singh B. Nested PCR analysis of Plasmodium parasites. Methods Mol Med. 2002;72:189-203.

18. Snounou G. Genotyping of Plasmodium spp. Nested PCR. Methods Mol Med. 2002;72:103-16.

19. Snounou G, Zhu X, Siripoon N, Jarra W, Thaithong S, Brown KN, et al. Biased distribution of msp1 and msp2 allelic variants in Plasmodium falciparum populations in Thailand. Trans R Soc Trop Med Hyg. 1999;93(4):369-74.

20. Soulama I, Nebie I, Ouedraogo A, Gansane A, Diarra A, Tiono AB, et al. Plasmodium falciparum genotypes diversity in symptomatic malaria of children living in an urban and a rural setting in Burkina Faso. Malar J. 2009;8:135

21. Atroosh WM, Al-Mekhlafi HM, Mahdy MA, Saif-Ali R, Al-Mekhlafi AM, Surin J. Genetic diversity of Plasmodium falciparum isolates from Pahang, Malaysia based on MSP-1 and MSP-2 genes. Parasit Vectors. 2011:4:233.

22. Agyeman-Budu A, Brown C, Adjei G, Adams M, Dosoo D, Dery D, et al. Trends in multiplicity of Plasmodium falciparum infections among asymptomatic residents in the middle belt of Ghana. Malar J. 2013;12:22.

23. Team RC. A language and environment for statistical computing. Vienna: $R$ Foundation for Statistical Computing; 2014

24. Oyedeji SI, Awobode HO, Anumudu C, Kun J. Genetic diversity of Plasmodium falciparum isolates from naturally infected children in northcentral Nigeria using the merozoite surface protein-2 as molecular marker. Asian Pac J Trop Med. 2013:6(8):589-94.

25. Amodu OK, Oyedeji SI, Ntoumi F, Orimadegun AE, Gbadegesin RA, Olumese PE, et al. Complexity of the msp2 locus and the severity of childhood malaria, in south-western Nigeria. Ann Trop Med Parasitol. 2008;102(2):95-102.

26. Aubouy A, Migot-Nabias F, Deloron P. Polymorphism in two merozoite surface proteins of Plasmodium falciparum isolates from Gabon. Malar J. 2003;2:12

27. Issifou S, Rogier C, Adjagba-Olakpo M, Chabi-Worou N, Ntoumi F. Complexity and genetic diversity of Plasmodium falciparum infections in young children living in urban areas of Central and West Africa. Parasitol Res. 2003;90(5):423-8.

28. Babiker HA, Lines J, Hill WG, Walliker D. Population structure of Plasmodium falciparum in villages with different malaria endemicity in east Africa. Am J Trop Med Hyg. 1997;56(2):141-7.

29. Branch OH, Takala S, Kariuki S, Nahlen BL, Kolczak M, Hawley W, et al. Plasmodium falciparum genotypes, low complexity of infection, and resistance to subsequent malaria in participants in the Asembo Bay Cohort Project. Infect Immun. 2001;69(12):7783-92.

30. Ghanchi NK, Martensson A, Ursing J, Jafri S, Bereczky S, Hussain R, et al. Genetic diversity among Plasmodium falciparum field isolates in Pakistan measured with PCR genotyping of the merozoite surface protein 1 and 2 . Malar J. 2010;9:1

31. Daniels RF, Schaffner SF, Wenger EA, Proctor JL, Chang HH, Wong W, et al. Modeling malaria genomics reveals transmission decline and rebound in Senegal. Proc Natl Acad Sci USA. 2015;112(22):7067-72.

32. Trape JF, Tall A, Diagne N, Ndiath O, Ly AB, Faye J, et al. Malaria morbidity and pyrethroid resistance after the introduction of insecticide-treated bednets and artemisinin-based combination therapies: a longitudinal study. Lancet Infect Dis. 2011;11(12):925-32.

33. Trape JF, Tall A, Sokhna C, Ly AB, Diagne N, Ndiath O, et al. The rise and fall of malaria in a West African rural community, Dielmo, Senegal, from 1990 to 2012: a 22 year longitudinal study. Lancet Infect Dis. 2014;14(6):476-88.

34. Noor AM, Mutheu JJ, Tatem AJ, Hay SI, Snow RW. Insecticide-treated net coverage in Africa: mapping progress in 2000-07. Lancet. 2009; 373(9657):58-67.

35. Mayor A, Saute F, Aponte JJ, Almeda J, Gomez-Olive FX, Dgedge M, et al. Plasmodium falciparum multiple infections in Mozambique, its relation to other malariological indices and to prospective risk of malaria morbidity. Trop Med Int Health. 2003;8(1):3-11. 
36. Owusu-Agyei S, Smith T, Beck HP, Amenga-Etego L, Felger I. Molecular epidemiology of Plasmodium falciparum infections among asymptomatic inhabitants of a holoendemic malarious area in northern Ghana. Trop Med Int Health. 2002;7(5):421-8.

37. Takala SL, Coulibaly D, Thera MA, Dicko A, Smith DL, Guindo AB, et al. Dynamics of polymorphism in a malaria vaccine antigen at a vaccinetesting site in Mali. PLoS Med. 2007;4(3):e93.

Submit your next manuscript to BioMed Central and we will help you at every step:

- We accept pre-submission inquiries

- Our selector tool helps you to find the most relevant journal

- We provide round the clock customer support

- Convenient online submission

- Thorough peer review

- Inclusion in PubMed and all major indexing services

- Maximum visibility for your research

Submit your manuscript at www.biomedcentral.com/submit 